

DERLEME / REVIEW

doi: 10.17986/blm.2018241706

\title{
Ani Bebek Ölüm Sendromu ve Adli Hemşirelik Yaklaşımı
}

\section{Sudden Infant Death Syndrome and Forensic Nursing Approach}

\author{
Ilknur Yıldız
}

Cumhuriyet Üniversitesi Sağlık Bilimleri Fakültesi Hemşirelik Bölümü, Sivas

\section{Özet}

Ani Bebek Ölüm Sendromu (ABÖS), hiçbir sağlık sorunu olmayan bir yaşın altındaki bebeklerin beklenmedik bir biçimde ve nedeni otopsi ile açıklanamayan ölümüdür. Dünyada ABÖS görülme sıklığı toplumlara göre değişmektedir. ABÖS gelişimsel, çevresel ve biyolojik risk faktörlerine bağlı gelişebilir. Bebeğin prematüre doğması, annenin sigara kullanması, bebeğin ebeveynle aynı yatakta uyuması ve yüz üstü pozisyonda yatması ABÖS riskini arttıran bazı faktörlerdendir. Ayrıntılı araştırma gerektiren ve adli olgu kapsamında değerlendirilen şüpheli ABÖS olgularında da araştırma ekibinin içinde yer alacak adli tıp konularında eğitimli adli hemşirenin olgunun değerlendirilmesinde ve çözümde önemli rolü bulunmaktadır. Aile ile yapılan görüşmelerde sorulan soruların, risk faktörlerini belirlemek ve bilgi toplamak amacıyla sorulduğu, suçlama amacı taşımadığı belirtilmelidir. Ölüm olayının araştırılmasında sağlanan katkı yanı sıra, ailelerin yaşadığı travmayla başetmelerini kolaylaştırmak için gerekli destek ve danışmanlık sağlanmalıdır. Ebeveynler stres, öfke, suçluluk ve ölümü kabul etmede güçlükler yaşayabilir. Bu kapsamda ailenin duygularını ifade etmesine olanak tanınmalı, ölümün doğrudan ailenin hatası sonucu olmadığı açıklanmalı ve ailenin suçluluk duyguları azaltılmalıdır.

Anahtar Kelimeler: Ani Bebek Ölüm Sendromu; Adli Hemşirelik; Ebeveyn.

\section{Giriş}

Ani Bebek Ölüm Sendromu (ABÖS), hiçbir sağlık sorunu olmayan bir yaşın altındaki bebeklerin beklenmedik bir biçimde ve nedeni otopsi ile açıklanamayan ölümüdür. Beşik ölümü olarak da adlandırılmaktadır (1-3). Dünyada ABÖS görülme sıklığı toplumlara göre değişmektedir. ABÖS insidansı 2004 yılında 1000 canlı doğumda Hollanda' da 0.09, Japonya'da 0.19, Kanada'da 0.24 , İngiltere'de 0.32 , ABD'de 0.55 , Avustralya'da 0.22

Sorumlu Yazar: Dr. Öğr. Üyesi İlknur Yıldız

Cumhuriyet Üniversitesi Sağhlk Bilimleri Fakültesi Hemşirelik Bölümü, Sivas

*Uluslararası III. Adli Hemşirelik II. Adli Sosyal Hizmet I. Adli Gerontoloji Kongresinde (12-14 Ekim 2017, Yozgat) sözel bildiri olarak sunulmuştur.

E-mail: ilknuryildiz@yahoo.com.tr

Geliș: 30.10.2017 Düzeltme: 26.03.2018 Kabul: 20.06.2018

\begin{abstract}
Sudden infant death syndrome (SIDS), is a sudden death of infants under one year of age with no health problems and unexplained autopsy. The frequency of SIDS in the world varies according to societies. SIDS may develop due to developmental, environmental and biological risk factors. Preterm birth of infant, mother's tobacco use, bed-sharing and prone sleeping position are some of the factors that increase the SIDS risk the risk of. In the case of suspected SIDS cases that require further investigation and evaluated within the scope of the forensic case, the educated forensic nurses in the forensic medicine to be included in the research team has an important role in the evaluation and resolution of the case. The forensic nurse should explain to the parents that the questions in the interviewing are designed to gather information and determine risk factors, not accuse the parents. Parents have difficulty in accepting the death of their baby and experience stress, anger and guilt. In this context, it should be allowed to express the feelings of the family, to explain that death is not is not the result of their own fault and to reduce family's guilt feelings.
\end{abstract} Parent.

Keywords: Sudden Infant Death Syndrome; Forensic Nursing;

olarak bulunmuştur $(4,5)$. Ülkemizde ABÖS sıklığına ilişkin yeterli veri bulunmamaktadır.

Çeşitli önleme kampanyalarına rağmen ABÖS bebek ölümlerinin önemli nedenlerinden biridir. ABD Bebek Ölüm İstatistikleri Raporu (2010)'na göre ABÖS, bebek ölüm nedenleri arasında üçüncü sırada yer almaktadır (6). Yaşamın ilk ayında daha az sıklıkta görülmekle beraber 2-4 ay arasındaki bebeklerde daha yaygındır $(7,8)$. ABÖS ölümlerinin yaklaşık \%90'ı yaşamın ilk 6 ayında gerçekleşir. ABÖS'da ölüm genellikle uyku esnasında olmaktadır (3). Cinsiyet farkının nedeni bilinmemekle birlikte erkek bebeklerde daha sık görülmektedir (7-9). Ailede ABÖS nedeniyle kaybedilen çocuk sayısı arttıkça risk daha da artmakta, mevsimsel olarak özellikle kış aylarında daha sık görülmektedir (5,7-9).

ABÖS'a neden olan mekanizmalar tam olarak bilinmemekle birlikte bazı hipotezler ortaya atılmıştır. İlk 
ortaya atılan hipotez uzamış apne nöbetleridir. Hipoksi ve otonomik disfonksiyon üzerinde de durulmaktadır (5,9-11). Filliano ve Kinney (1994) hassas bebek, kritik gelişimsel periyot, diş etkenler olarak üçlü risk hipotezi yayınlamıştır (12). Patofizyolojide apne, hipoksi, kardiyorespiratuvar kontrolde yetersizlik, kardiyovasküler patolojiler, enfeksiyonlar ve metabolik hastalıkların rol oynadığ 1 belirtilmektedir $(9,13,14)$.

\subsection{Risk Faktörleri}

Postneonatal ölümlerin en yaygın nedeni olan ABÖS gelişimsel, çevresel ve biyolojik risk faktörlerine bağlı gelişebilir. Karmaşık ve çoklu risk faktörlerinin henüz yeterince anlaşılamadığı ancak özellikle çevresel risk faktörlerinin düzeltilebilir olduğu belirtilmektedir (9). ABÖS ile ilişkili anneye ve doğuma ait değiştirilen ve değiştirilemeyen risk faktörlerinin araştırıldığ mada annenin sigara kullanımı, annede kronik hipertansiyon, gestasyonel hipertansiyon, prematüre doğum, intrauterin gelişme geriliği ve ikiz olmanın öne çıkan risk faktörleri olduğu belirlenmiştir (15).

Bebeğin yatış pozisyonu ile ABÖS arasında güçlü bir ilişki olduğu ölümlerin çoğunun yüz üstü yatış pozisyonunda gerçekleştiği bulunmuştur (16,17). Amerikan Pediatri Akademisi (APA) sağlıklı her bebeğin sırtüstü yatırılmasını önererek, 1994 yılında bebekleri sırtüstü yatırma kampanyası (Back-to-Sleep Campaign) başlatmıştır. Sırtüstü yatırma kampanyalarıyla birlikte ABÖS kaynaklı bebek ölümlerinin önemli ölçüde azaldığı belirlenmiştir (2,18). ABD'de 2004 yılında yayınlanan bir çalışmada ABÖS ölüm oranının \%53 azaldığ bulunmuştur (19). Bebeği yüz üstü pozisyonda yatırma oranının 1992'de \%70 iken 2010 yilında \%13.5'e düştüğü belirlenmiştir (20). Bebeğin yumuşak yatakta yatması ve yatak paylaşımı ABÖS riskini arttırmaktadır. Yumuşak yatak kullanımı ile birlikte yüz üstü yatış pozisyonu ABÖS riskini 20 kat arttırmaktadır $(21,22)$. Bu amaçla 2016'da APA tarafından yayınlanan rehberde sırt üstü yatış pozisyonu ile birlikte bebeğin uyku çevresinin güveli hale getirilmesi, bebeklerin sert uyku yüzeyinde yatırılması, yatakta yumuşak objelerin bulundurulmaması ve yatak paylaşımının olmaması önerilmektedir (2).

Doğum öncesi yetersiz bakım alma, düşük doğum ağırlığı, preterm doğum, intrauterin büyüme geriliği gibi gebelikle ilgili bazı faktörlerin ABÖS riskini arttırdığ 1 belirtilmektedir $(9,23)$. Gebelikte ve doğum sonrası sigara kullanımı ve bebeğin çevresel sigara dumanına maruziyeti ABÖS ile ilişkili bulunmuştur (24-26). Sigara kullanımıyla birlikte yatak paylaşımı varsa risk daha da artmaktadır (27). Riski azaltmak amaciyla gebelikte ve doğum sonrası bebeğin bulunduğu ortamda sigara içilmemesi önerilmektedir (24-28).

Emzirme ve emzik kullanımının ABÖS'ün önlenmesinde koruyucu olduğu bildirilmektedir. (29-31). Hauck ve ark. (32) meta analizinde bebeğin emzikle uyumasının bebeği ABÖS'den korumada önemli bir faktör olduğunu bulmuştur. ABÖS riskini azaltmak için bebek emmeye iyice alıştıktan sonra emzik kullanımı önerilmektedir (32). ABÖS vakalarını doğumda veya öncesinde tanımlamak için mevcut herhangi bir yöntem bulunmamakla birlikte korunma risk faktörlerinin kontrol altına alınmasına dayanır. Ülkemizde ABÖS risk faktörlerini belirlemek amacıyla yapılan çalışmada bir annelerin ABÖS risk faktörleri ve önlemeye yönelik yaklaşımlar konusunda bilgiye ihtiyaçlarının olduğu belirlenmiştir (33). ABÖS gelişimini önlemek için bebeğin sırtüstü pozisyonda sert yatak yüzeyinde uyutulması, anne yanında ayrı yatakta yatırılması, gebelik ve doğum sonrasında sigara maruziyetinden kaçınılması, anne sütü ile beslenme ve emzik kullanımı konusunda eğitilmesi önerilmektedir.

Tablo 1. ABÖS Risk Faktörleri.

\begin{tabular}{|l|l|}
\hline Anneye ait Risk Faktörleri & $\begin{array}{l}\text { Bebeğe ait Risk } \\
\text { Faktörleri }\end{array}$ \\
\hline $\begin{array}{l}\text { Annenin gebelik süresince } \\
\text { sigara, alkol, ilaç kullanımı }\end{array}$ & $\begin{array}{l}\text { Yaş (2-4 aylarda risk } \\
\text { fazla) }\end{array}$ \\
\hline $\begin{array}{l}\text { Prenatal ya da postnatal } \\
\text { bakımın yetersiz olması }\end{array}$ & Erkek cinsiyet \\
\hline $\begin{array}{l}\text { Düşük sosyoekonomik } \\
\text { düzey }\end{array}$ & Prematürelik \\
\hline $\begin{array}{l}\text { Anne yaşının 20'den } \\
\text { küçük olması }\end{array}$ & $\begin{array}{l}\text { Yüzüstü ve yan yatış } \\
\text { pozisyonu }\end{array}$ \\
\hline $\begin{array}{l}\text { Eğitim düzeyinin düşük } \\
\text { olması }\end{array}$ & $\begin{array}{l}\text { Son zamanlarda } \\
\text { geçirilmiş enfeksiyon ya } \\
\text { da ateş varlığı } \\
\text { Bebeğin yumuşak } \\
\text { yekar anne olması/yastıkta }\end{array}$ \\
\hline yatırılması
\end{tabular}

Kaynak: Hunt CE, Hauck FR. Sudden infant death syndrome. CMAJ 2006;174(13):1861-69. 


\subsection{Tanı}

Bebek ölümünün kaza dışı olup olmadığının belirlenmesi önemlidir. ABÖS tanısı koyabilmek için önce olası tüm hastalıklar ve ölüm nedenleri dışlanmalıdır. Bu nedenle tam bir araştırma için ayrıntılı otopsi, olay yeri incelemesi bebek ve ailenin öyküsü içeren standart protokoller uygulanmalıdır $(29,30)$.

Bazı vakalarda ölümcül çocuk istismarı ani bebek ölüm sendromu ile karıştırılabilir. Otopside ABÖS ve yumuşak bir obje ile tesadüfi veya kasıtlı boğulmaları ayırt etmek zordur (34). Altı aydan büyük bebek ölümleri, eş zamanlı ikiz bebek ölümü, tekrarlayan siyanoz, apne, ağız ve burun kanamaları, açıklanamayan kardeş ölüm öyküsü olan olgular istismarı düşündürebilir (35).

\subsection{Adli Hemşirelik Yaklaşımları}

ABÖS şüpheli olguların adli olgu kapsamında değerlendirilmesi gerekir. Ani beklenmedik bebek ölümlerinde ölüm nedenini belirlemek adli tıp açısından zor bir süreçtir (36). ABÖS olgularında ölümün araştırılmasında ve açıklanmasında adli hemşirenin önemli rolleri bulunmaktadır (8). Adli tıp ölüm araştırmaları sistemlere göre değişmekle birlikte adli hemşirelerin kayıt tutma, konuya ilişkin bilgi toplama, olay yeri araştırması, adli rapor hazırlama, adli ekip üyeleri arasında bilgi akışını sağlama, aileye bilgi verme ve destek olma, gerektiğinde tanıklık yapma gibi kapsamlı görevleri bulunmaktadır (38-40). Adli tıp konularında eğitimli adli hemşireler, ekip çalışması içinde adli olayın çözümüne katkı sağlayabilir. Gelişmiş ülkelerde adli hemşireler ölüm araştırmalarında yer almakta ve adli araştırma ve otopsinin önemi nedeniyle hekim ve hemşireler ABÖS eğitimini birlikte almaktadır $(40,41)$.

Adli hemşirelerin ABÖS araştırmalarında uygulanan süreci bilmeleri gerekir. ABÖS ölümlerinde genellikle sağlıklı bebek gece beslenir ve beşiğine konur. Ertesi sabah ebeveynler bebeğini soğuk, mor ve tepkisiz şekilde bulur. Acil ekibi çağrılır ve acil servis protokolüne göre bebek ya acil servise götürülür ya da evinde kalır. Eğer evinde kalırsa adli tıbbi muayene için incelemeyi yapacak ekip olay yerine ulaşana kadar bebeğe ve odasına dokunulmamalıdır (8). Bebeğin ölüm nedeni ve şeklini belirlemek için eğitimli personelin tam ve doğru olay yeri araştırması yapması son derece önemlidir. Araştırma gerektiğinde, oyuncak bebek kullanarak yapılan canlandırmanın video kaydı, fotoğraflama, şekil çizimlerini içeren standart bir formatta yapılabilir. Bebeğin yatak odasının şekli ve 1sısı belirlenir. Bebeğin ölmeden önceki durumuyla (sağlık durumu, en son beslenme zamanı, gece kontrol edilip edilmediği, uyuma pozisyonu, bebek ölü bulunduğundaki durumu) ilgili bilgi elde etmek amacıyla ebeveynlere sorular sorulur (42-44).
Bebeğin ölü olduğu tespit edildikten sonra acil servise getirilirse adli tıbbi muayene için ilgili birimlere bildirilir. Olay yeri incelemesi, bebeğin ölümünde etkili faktörleri belirlemesinde önemlidir $(8,43)$. Adli hemşireler, temel bilgi ve becerilerine ek olarak adli olaylardaki tecrübeleri nedeniyle olay yerinde inceleme yapan diğer profesyonelleriyle işbirliği içinde olay yeri incelemesine, dolay1sıyla ölümün aydınlatılmasına önemli katkı sağlayacaktır. (24). Olay yeri incelemesi tamamlandiktan sonra toplanan bilgiler dış muayene ve ardından otopsiyi gerçekleştirilecek hekime bildirilir (8). Tüm olgularda, ölüm nedenine belirlenebilmesi için eksiksiz bir diş muayene ile retinal hemoraji araştırması da dahil olmak üzere, ayrıntı11 toksikolojik incelemeyi de içeren otopsi önemlidir (43).

\subsection{Ani Bebek Ölümleri Olay Yeri Araştırmasında Adli Hemşirelerin Sorumlulukları}

- Önleme ve müdahale stratejileri geliştirme

- Multidisipliner ekip üyeleriyle çalışma ve eğitim

- Multidisipliner ekipteki profesyonel olgu incelemelerine katılma

- Kanita dayalı uygulamalar yapma ve protokoller geliştirme

- Bir bebek ölüm araştırmasını yürütme, bir ani bebek ölüm araştırması görüşme raporu doldurma ve oyuncak bebekle yapılan bir canlandırmayı yürütme

- Bebek ölümleri incelemesi ve olay yeri araştırma bulgularına dayalı olarak bebeklerin sağlığını ve güvenliğini etkileyen yasalarla ilgili çalışma

- Bebek ölümleri olay yeri araştırmasına ilişkin politika ve prosedürleri düzenleyen kuruluşlara yardım etme

- Yenidoğan ve bebekler büyüme gelişme gibi alanlarda eğitimler alma

- Araştırma yapma

- Gelecekte ölümleri önlemek için stratejiler uygulama şeklinde sıralanabilir (42).

Ebeveynler ani gerçekleşen ölümü kabul etmede güçlükler yaşayabilir. Stres, öfke ve suçluluk en sık görülen tepkilerdir. Aileyle ölüm hakkında görüşmek ve uzun süre otopsi sonuçlarını beklemek duygusal stresi artırır (8). Yapılan tüm işlemler açıklanmalı, travmalı olgulardaki görüşme tekniklerine uygun bir dil kullanılmalıdır. Adli hemşireler, aileye ölüme yol açan olası mekanizmaları belirlemek amacıyla yapılan araştırmanın rutin bir araştırma olduğunu açıklamalıdır. Yapılan görüşmelerde sorulan soruların, risk faktörlerini belirlemek ve bilgi toplamak amacıyla sorulduğu, suçlama amacı taşımadığı belirtilmelidir. Ölüm nedeniyle şokta olan aileden öykü alınırken açık uçlu sorular sorulmalı, toplanan bilgilerin 
adli tıp ekibi tarafından kullanılacağı vurgulanmalıdır. Ani ölüme yol açan mekanizmaları ve etiyolojiyi belirlemek için yapılan otopsinin tıbbi ve yasal açıdan gerekli olduğu açıklanmalıdır $(8,44)$. Bebeğin ani ölümü nedeniyle ebeveynler hassas ve zor bir dönem yaşadıkları için adli hemşireler olay yeri araştırmasında ve öykünün alınmasında aktif sorumluluklar üstlenebilir. Ailelerin duygularını ifade etmesine olanak sağlanırken, yaşadığı travmayla baş etmelerini kolaylaştırmak için gerekli destek ve danışmanlık sağlanmalı, gerektiğinde grup terapilerine yönlendirilebilir $(5,8,11)$.

Sonuç olarak adli hemşireler ABÖS olgularının yönetimi konusunda eğitilmeli ve adli ekip üyeleriyle koordine çalışarak uygun yaklaşımlar geliştirmelidir. ABÖS'nun önlemesine yönelik aileler bilinçlendirmeli, olgu yönetimi ve bildirimi konusunda standart prosedürler geliştirilmeli ve yas sürecinde aileye destek olunmalıdır.

\section{Kaynaklar}

1. Willinger M, James LS, Catz C. Defining the sudden infant death syndrome (SIDS): deliberations of an expert panel convened by the National Institute of Child Health and Human Development. Pediatr Pathol. 1991;11(5):677-684. doi: 10.3109/15513819109065465

2. AAP Task Force on Sudden Infant Death Syndrome. SIDS and other sleep-related infant deaths: updated 2016 recommendations for a safe infant sleeping environment. Pediatrics 2016;138(5):1-8. doi: 10.1542/peds.2016-2940

3. Fincancı ŞK, Kırangil B. Ani çocuk ölümleri sendromu. Türk Patoloji Dergisi 1988;4(2):56-59.

4. Hauck F, Tanabe K. SIDS. BMJ Clin Evid. 2009;315:1-14.

5. Celasin NŞ. Ani Bebek Ölümü Sendromu. Genç RE ve Özkan H (ed) Ebeler için Yenidoğan Sağlığı ve Hastalıkları. Akademi Nobel Tıp Kitabevleri.1. Baskı, Elazı̆̆,2016.

6. Matthews TJ, MacDorman MF. Infant mortality statistics from the 2010 period linked birth/Infant death data set. National vital statistics reports; 62(8). Hyattsville, MD: National Center for Health Statistics. 2013.

7. American Academy of Pediatrics, Task Force on Infant Sleep Position and SIDS. Changing concepts of sudden infant death syndrome: Implications for infant sleeping environment and sleep position. Pediatrics 2000;105: 650-656.

8. Koehler SA. Sudden infant death syndrome deaths: The role of forensic nurses. J Forensic Nurs. 2008;4(3):141-142. doi: 10.1111/j.1939-3938.2008.00023.x.

9. Hunt CE, Hauck FR. Sudden infant death syndrome. CMAJ 2006;174(13):1861-1869. doi: 10.1503/cmaj.051671

10. Gökçe S, Baysal SU. Ani Bebek Ölüm Sendromu. İstanbul Tıp Fakültesi Mecmuası 2004;67:56-61.

11. Atılmış ÜÜ, Dokgöz H, Yemişcigil A. Ani bebek ölümü sendromu. Adli Tıp Bülteni 2006;11(1):30-39.

12. Guntheroth WG, Spiers PS. The triple risk hypotheses in sudden infant death syndrome. Pediatrics 2002; 110: e64. doi: $10.1542 /$ peds.110.5.e64
13. Kahn A, Groswasser J, Franco P, Scaillet S, Sawaguchi T, Kelmanson I, et al. Sudden infant deaths: stress, arousal and SIDS. Early Hum Dev. 2003;75:147-166.

14. Klaver EC, Versluijs GM, Wilders R. Cardiac ion channel mutations in the sudden infant death syndrome. Int J Cardiol. 2011;152(2):162-70. doi: 10.1016/j.ijcard.2010.12.051.

15. Friedmann I, Dahdouh EM, Kugler P, Mimran G, Balayla J. Maternal and obstetrical predictors of sudden infant death syndrome (SIDS). J Matern Fetal Neonatal Med. 2017;30(19):2315-2323. doi: 10.1080/14767058.2016.1247265.

16. 1Gilbert R, Salanti G, Harden M, See S. Infant sleeping position and the sudden infant death syndrome: systematic review of observational studies and historical review of recommendations from 1940 to 2002 . Int J Epidemiol 2005;34:874-887. doi:10.1093/ije/dyi088

17. Ponsonby AL, Dwyer T, Gibbons LE, Cochrane JA, Wang YG.Factors potentiating the risk of sudden infant death syndrome associated with the prone position. N Engl J Med 1993;329: 377-382. doi: 10.1056/NEJM199308053290601

18. Malloy M.Trends in postneonatal aspiration deaths and reclassification of sudden infant death syndrome: impact of the "Back to Sleep" program. Pediatrics 2002;109:661-665.

19. Mathews TJ, MacDorman MF. Infant mortality statistics from the 2004 period linked birth/infant death data set. Natl Vital Stat Rep 2007;55(14):1-32.

20. Matthews R, Moore A. Babies are still dying of SIDS. Am J Nurs. 2013 Feb;113(2):59-64. doi: 10.1097/01. NAJ.0000426692.19202.5a.

21. Hauck FR, Herman SM, Donovan M, Iyasu S, Merrick Moore $\mathrm{C}$, Donoghue E, et al. Sleep environment and the risk of sudden infant death syndrome in an urban population: the Chicago Infant Mortality Study. Pediatrics 2003;111:1207-1214.

22. Tappin D, Ecob R, Brooke H. Bedsharing, roomsharing, and sudden infant death syndrome in Scotland: a casecontrol study. J Pediatr 2005;147:32-37.doi: 10.1016/j. jpeds.2005.01.035

23. Getahun D, Amre D, Rhoads GG, Demissie K. Maternal and obstetric risk factors for sudden infant death syndrome in the United States. Obstet Gynecol 2004; 103: 646-652. doi: 10.1097/01.AOG.0000117081.50852.04

24. Schoendorf KC, Kiely JL. Relationship of sudden infant death syndrome to maternal smoking during and after pregnancy. Pediatrics 1992;90:905-8.

25. MacDorman MF, Cnattingius S, Hoffman HJ, Kramer MS, Haglund B. Sudden infant death syndrome and smoking in the United States and Sweden. Am J Epidemiol. 1997;146(3): 249 -257

26. Alm B, Milerad J, Wennergren G, Skjaerven R, Oyen N, Norvenius G, et al. A case-control study of smoking and sudden infant death syndrome in the Scandinavian countries, 1992 to 1995. The Nordic Epidemiological SIDS Study. Arch Dis Child. 1998;78(4):329-334.

27. Vennemann MM, Hense HW, Bajanowski T, Blair PS, Complojer C, Moon RY, et.al. Bed sharing and the 
risk of sudden infant death syndrome: can we resolve the debate? J Pediatr 2012;160:44-48 doi: 10.1016/j. jpeds.2011.06.052.

28. Yıkılkan H, Ünalan PC, Uzuner A. Ani bebek ölümü ve nedenlerinden biri olarak annenin sigara içiciliği. Çocuk Dergisi 2007;7(4):227-232.

29. Hauck FR, Thompson JMD, Tanabe KO, Moon RY, Vennermann MV. Breastfeeding and reduced risk of sudden infant death syndrome: a meta-analysis. Pediatrics 2011; 128 (1):103-110. doi: 10.1542/peds.2010-3000.

30. Mitchell EA, Taylor BJ, Ford RP, Stewart AW, Becroft DM, Thompson JM, et al. Dummies and the sudden infant death syndrome. Arch Dis Child 1993;68(4):501-504.

31. Li DK, Willinger M, Petitti DB, Odouli R, Liu L, Hoffman HJ. Use of a dummy (pacifier) during sleep and risk of sudden infant death syndrome (SIDS): Population based case control study. BMJ 2006:332;18-22. doi: 10.1136/ bmj.38671.640475.55

32. Hauck FR, Omojokun OO, Siadaty MS. Do pacifiers reduce the risk of sudden infant death syndrome? A meta-analysis. Pediatrics 2005:116 (5); 716-723. doi: 10.1542/peds.2004-2631

33. Çalışır H, Özvurmaz S, Tuğrul E. Aydın il merkezindeki 0-11 aylık bebeklerde ani bebek ölümü sendromu (ABÖS) ile ilgili risk faktörlerinin incelenmesi. C.Ü. Hemşirelik Yüksek Okulu Dergisi 2007; 11(2):7-17.

34. American Academy of Pediatrics, Hymel KP; Committee on Child Abuse and Neglect; National Association of Medical Examiners. Distinguishing sudden infant death syndrome from child abuse fatalities. Pediatrics 2006;118(1):421-427. doi: $10.1542 /$ peds.2006-1245
35. Ardıç Ş. Ani İnfant Ölüm Sendromu. Sunum. URL: http://file. atuder.org.tr/_atuder.org/fileUpload/BW14BzPUoP44.pdf

36. Pakiş I. Ani beklenmedik bebek ölümlerinde adli boyut ve ayırıcı tanı yöntemleri. Türkiye Klinikleri J Foren Med 2009;6(1):23-31.

37. Yılmaz R, Pakiş I, Turan N, Can M, Kabakuş Y, Gürpınar S. Adli Tıp Birinci Adli Tıp İhtisas Kurulu'nca ölüm sebebi verilen 0-1 yaş grubu bebeklerin ölüm sebebi açısından değerlendirilmesi. Türk Ped Arş; 2010; 45: 31-36.

38. Çevik SA, Başer M. Adli hemşirelik ve çalışma alanları. Sağlık Bilimleri Dergisi 2012;21(2):143-152.

39. Fırat S, Ünal S, Geleş ÇY. Hemşirelikte yeni bir alan: Adli hemşirelik. Adli Tıp Bülteni, 2016; 21(1): 39-42. doi: 10.17986/blm.2016116599

40. Eşiyok B, Hancı İH, Özdemir Ç, Yelken N, Zeyfeoğlu Y. Adli hemşirelik. Sted 2004;13(5):169-171

41. Koehler SA. The importance of a forensics investigation of sudden infant death syndrome: recommendations for developing, low and middle income countries Acta Medica Academica 2010;39:165-174.

42. Tabor PD, Ragan K. Infant death scene investigation J Forensic Nurs. 2015;11(1):22-27; doi: 10.1097/ JFN.0000000000000057.

43. Berkowitz C. Sudden infant death syndrome, sudden unexpected infant death, and apparent life-threatening events. Advances in Pediatrics 2012;59:183-208. doi: 10.1016/j. yapd.2012.04.011

44. Cullen D, Oberle M, Elomba CD, Stiffler D, Luna G. Illustrations of unexpected infant sleep deaths. J Forensic Nurs. 2016;12(3):141-146. doi:10.1097/JFN.0000000000000120. 